\title{
Research on Teaching Mode Reform of the Chinese in Primary School under the Background of the New Standard
}

\author{
Yan Li \\ Qingdao Economic \& Technological Development Area No.2 \\ Experimental Primary School \\ Qingdao, Shandong, China \\ liyanvs1@126.com \\ Wen Jiang \\ Qingdao Experimental Primary School \\ Qingdao, Shandong, China
}

\author{
Yingchun Zhuo \\ Qingdao West Coast New Area Jimiya Primary School \\ Qingdao, Shandong, China
}

Jiangbo Chen*

Qingdao Huanghai University

Qingdao, Shandong, China

\begin{abstract}
Chinese is important in the system of subject of primary school very much. It plays a pivotal role in the accumulation of living experience, the transmission of nationality spirit, the conservation of humanity spirit and the cultivation of vitality idea. As we all know, it is the implementation of new curriculum standards "people-oriented" concept, students focus on "comprehensive" development. However, the current situation of Chinese class is perishing in our country, the traditional teaching model is being questioned. This paper specifically focuses on the study of Chinese in primary school under the background of the new standard. It conducts this study mainly through the combining method of theory summary and survey analysis, which would properly design the strategy, process and concrete effects. It intends to offer some valuable advice both in theory and practice to teachers of Chines, inspiring and guiding the current teaching of Chinese and be some help to the new curriculum reform of Chinese teaching.
\end{abstract}

Keywords-Primary school Chinese; Teaching design; Teaching reform; New standard

\section{INTRODUCTION}

The new Chinese course standards clearly define the "humanity" as the important content of Chinese subjects, and confirm the requirements for Chinese subjects to enhance the independent thinking ability of students, especially students, especially the independent logic judging ability [1]. The new course reform also raise the teaching objectives in three aspects, the knowledge and capacity, the process and methods, the emotions, attitudes and values, trying to change the traditional knowledge-based classroom teaching situation. Meanwhile, a new round of course reform follows the principle "student development-oriented", advocates for all students the promoting the all round development of students; Pays attention to student diversity, to promote the development of each individual student; Considers the students sustainable development. According to the new course standards and it's principle described above, the Chinese education should be "human-oriented", to foster the Chinese culture and a wide range of capabilities of student, to be "student-centered" indeed and return to" human education" finally, with it's multiple educational functions.

The new course standards bring not only the new education ideas but also the new challenges to the front line teachers. The education of our country is worried. In the classroom the teaching method is single. It is based that teachers explain and students response. Students lack interest in classroom learning and awareness. So it is difficult to develop students awareness of innovation. It is the key to change the current status that lies in the classroom teaching. It is the core, the most fundamental and most important aspect is the design of classroom teaching. To optimize the design of the classroom teaching, to correctly handle the teaching content, teaching target, teaching form, the relationship between as long as its connotation and characteristic analysis, the principles of design course can be, only follow the principle of curriculum design, based on the teachers design classroom lessons, to make the classroom has the characteristics of life classroom is generated, and then burst out of the classroom teaching full of vitality.

\section{LEARNING Plan TEACHING MODE}

"Learning plan" is a kind of learning resource which is shared between teachers and students. It is a designed learning plan with teaching synergetic function on the basis of the unit for the class which textbooks and other teaching-aided resources. It is developing to become a kind of teaching model which needs to take the "learning plan" as a carrier, and should instruct students to realize self-regulated learning, cooperative learning and learning in the "Chinese teaching activities". It makes focus on and analyze the learning situation, teach based on the learning situation [2].

The other achievement is optimizing teaching structure. It has a great impact on constructing classroom teaching structure based on "learning priority. We should understand its 
characteristics: take the problems as the start point for teaching, take teaching activities based on learning factors, organize different levels of exercise, and give timely feedback and adjustment based on the learning aims. The optimization can be reflected from these aspects: develop the definition of "lesson", create new lesson types, enrich Chinese learning activities. The learning assessment should be found in all teaching process, and asynchronous teaching activities are increased.

The focus of learning plan is to ask the students to study actively and effectively, with the help of the plan, teachers only act as directors. This plan is well prepared by the teacher according to every unit and given to the students. It includes the following: how the weather is, how good the mood is and how well the students are. The aim of this lesson. Instructions for learning methods. The knowledge structure. Students' own knowledge structure. Analyses about the difficult points and the important points. Test oneself. Columns of the students' grades. One's own puzzles. Knowledge related to what one has known.

When Learning plan is carried out, Teachers must strengthen the independent study and peer consultations, develop the rational understanding of the Guided Learning Plan in the teaching of Chinese education in primary school, interpret and practice accurately the request of the standard of Chinese curriculum in primary school, design perfect Learning Plan of Chinese, teach Chinese in combination with the Plan, and attach importance to the teaching feedback and consideration. And for students, they should realize that they themselves are the main roles of Chinese study, and they should make full use of the Plan before, in and after the lectures. Lastly, in the school, inspiring teacher-student evaluation system and effective management mechanism should be established for the implementing of the work of the Plan [3].

\section{PBL TEACHING MODEL}

PBL (Problem-Based Learning) is an effective problembased educational concept. It belongs to a kind of new teaching model, which places learning in complex, undesirable, authentic problem situations, and allows students to analysis problem, learn scientific knowledge underlying the problem, thus develops problem-solving skills that can help them get answers of problem in real world step by step as well as develops their independent learning abilities. It is a kind of teaching methods, which based on the Problem and in conformity with the theory of constructivism. This method can develop learners' thinking, cultivate students' ability of finding, analyzing and solving problem.

The basic process of PBL instructional design, including: how to create a learning atmosphere, to great problem situations, exploration of the problem, the formation and evaluation of results and the role of students in the process and the effect of teachers. The process and reflection of teaching and the analysis through comparing teaching effect of the experiment group and the opposite one before and after teaching; feedback from students after teaching. Teaching process is as follows: created problem situation to arouse students' interest-identified the major problem and gave the role to students-discussed the problem and determined the starting conditions-collected and analyzed information-solved new issues-made plan and solved the problem-switched roles and enhanced students' experience [4].

The emergence and development of students' cooperation behavior in PBL is influenced by many factors. Project based Teaming is a long-term process, it is about an entire semester, The key to its success is a few points: project design should not only focus on the teaching objectives and teaching content, but also can cooperate motivating students at the same time should pay attention to moderate difficulty. The beginning of cooperation should deepen students' understanding of PBL, and can be enable to have a clearer idea in the completion of project tasks, cohesion among project tasks to arrange appropriate. Teacher's guidance, coordination, timely urge and encourage are also important for the team cooperation development. The teacher may carry on training and guidance is not regularly on small group leader to have the skills. Teachers should make policy guidance for students at the beginning of cooperation, to cultivate students' ability of expression, and proposed the question, cooperate to complete the task etc. It is necessary to establish multiple evaluation criteria corresponding to real-time evaluation, teachers, students involved evaluation to stimulate and maintain student cooperation enthusiasm.

\section{Situational TEACHING MODEL}

Situation Teaching Model requires teachers to create a situation close to nature through a variety of teaching methods to help students by using situational awareness, understanding and mastering learning content, stimulating students' thinking, and developing communicative skills. Teachers present the teaching contents with vivid and intuitive form in front of students through pictures, objects, games, songs, multimedia, etc. Situation Teaching Model uses abstract knowledge to show an image of a scene and helps language learners understand and master that knowledge in rich language scenarios. Thus it could provide students with comprehensive language input, effectively reducing the students' studying difficulties [5]. Meanwhile the classroom becomes interesting and entertaining. This pedagogy meets the cognitive characteristics of the student's age in primary school and can stimulate students motivation to learn and maintain lasting interest in learning and help students put what they learn into practice. Especially in the actual teaching, it can develop students' practical ability to operate in line with the current requirements of cultivating students' innovative consciousness.

Situational Teaching Model emphasize that the teacher should design some situations creative in the course of teaching to excite the students' initiative and independence. At present, there are some problems in Chinese situational teaching: relying too much on the quality of teachers, operating system of teachers being not perfect, the implementation effect being not easy to evaluate; Effective Chinese situation teaching should have the following characteristics: situational creation should be challenging, situational teaching should embody emotionality, authenticity and integrity. Then, it puts forward the specific ways of implementing the life situational teaching in primary school Chinese course according to its current actual 
situation in primary school: the creation of life situations, situations induction to stimulate students' desire to learn; adding life backgrounds, situational analysis to activate the classroom atmosphere; flexible adoption of life experience, sharing context to enliven textbooks; application of life experience, the situations returning to understand the value of knowledge.

Situational Teaching Model gets a satisfactory effect in the classroom. The creation of situational teaching requires the teacher not only to contact with the teaching material closely but also to be familiar with his/her students' development characteristics, make the Chinese study to be a urgent requirement for students, conduct them to consider and resolve question in Chinese then achieve the favorable teaching effect. Teachers should create a wide range of reading the classroom:

(1)Combination of a variety of situations;

(2)Create a game situation, increase the fun;

(3)Role play, create experience situation; create close to the student life reading situation; teachers themselves Love "action" situation [6].

Students should understand the characteristics and needs of students; teaching methods, training habits:

(1)To develop the habit of pre-class preview;

(2)To develop while reading the habit of thinking;

(3)Training students to observe the ability to expand student thinking.

Situational Teaching Model hopes to promote the students' development in an all-around way and harmonious development by unify the acknowledge and the emotion in the course of teaching. It will help us to optimize teaching, change the way of leaning, enrich our resources and widen the way of leaning to research The Situational Teaching. The figurativeness, honest, emotion interest and reason of The Situational Teaching make it scientific method.

\section{FLIPPED CLASSROOM TEACHING MODEL}

Flipped Classroom Model changes teaching activities of traditional classroom in class and after class.After class, students study by themselves according to high quality teaching resources the teachers provided in class, accomplish the transmission of knowledge, and can timely communicate with the teacher and student online, and record the problems encountered in the learning. And in class, teaching process are interactive activities between teachers and students to absorb knowledge.

Base on the literature research, drawing on lessons from the existing models and elaborate, this paper builds one flip classroom model--"Two main aspects three sections and seven finks" Flipped Classroom Model. "Two main aspects" is teacher-led and students-body. "Three sections" is before class, in class and after class. "Seven finks" is teaching preparation, transfer knowledge, guide internalization, teaching reflection, and knowledge acquisition, knowledge internalization, learning summary. Secondly, based on the model design teaching, take
Chinese courses in Primary school for example. Respectively design learners, learning content, learning objectives, learning strategies, learning resources, learning environment, learning activities and learning evaluation[7].

Then combining with the result of case study, the scale about interaction and teaching effect is compiled. The former has four variables including interactive way, interactive content verbal behavior and nonverbal behavior, while the later six, including interactive satisfaction, learning interest, collaborative learning, self-learning, innovation ability and solving problem. According to the opinions of the experts and the project analytic result of the questionnaire, we modify scale to form formal questionnaire, as a measuring tool for further empirical research.

In order to make the Chinese teaching methods have a further development. It puts forward many specific teaching strategies which basis on the problems and related factors. In Preparation period of teaching, including the improving strategy of task leading learning, self-study by video, setting exercise. In teaching period in class, the teacher should pay attention to the improving strategy of solving the puzzle, showing what have learned, bettering the teamwork, testing in the class, concluding the class. And the teachers should consider different sides, such as the different dimensions, different subjects and different methods in evaluation. Finally, it's the part of rethink and conclusion. This part analyzing the inner disadvantages of the flipped class model, to lead educators to know and use the model correctly.

The results are analyzed by SPSS. The results of the experiment show that the flipped classroom teaching mode can significantly improve primary students' Chinese learning interest. The autonomous learning ability of the students is enhanced, especially in learning motivation, learning time, learning method, learning achievements and innovation ability. Students' Chinese proficiency has significant improvement. Therefore, it is feasible to apply the flipped classroom teaching mode in primary school Chinese teaching.

\section{SUMMARY}

The development of students' learning autonomy is not achieved overnight. Therefore, teachers should make develop students' learning autonomy as its own duty; they should transfer teaching ideas by changing the "excessive teaching" to giving students autonomy, combine self-learning and cooperation learning deeply, guide students to change learning behavior, and need to trust and encourage students (including care, respect, entrusts with an important task and the establish incentive mechanism, etc.). Thus, students' learning autonomy can get long-term development.

Language classroom is the source of students to learn knowledge, the new curriculum standard emphasizes to change teaching idea and teaching way, to create a new teaching pattern. The language classroom "effective thinking" has formed take the student as the main body, to the equality of teachers as the leading collaborative relationship between teachers and students, good classroom teaching can make students' knowledge and ability, process and methods, emotional attitude and values to obtain the comprehensive 
promotion. These models are the objective requirement of new curriculum reform, the liberation of the student's nature, and it also cultivate the students' creativity and love of life through their active on life observation, discover, explore and validation. I hope that in the process of primary and secondary school education reform, these models can be thoughtprovoking and gives some enlightenment and reference to the education workers and front-fine teachers.

\section{REFERENCES}

[1] Wang Shiyou. Chinese Teaching in Middle and Primary Schools under the Information Technology Background [J]. Curriculum, Teaching Material and Method, 2014 (9):37-42

[2] Liu Liming, Qi Zhanyong. On Liu Fonian's Thoughts of Teaching Reforms in Primary and Middle Schools [J]. Journal of East China Normal University(Educational Sciences), 2014(3):1-9

[3] Shi Xiaoling, Yu weitao. Reflection and Multi-innovation of Teaching Models in Middle and Primary Schools--Based on Reflection on Class Teaching Reform in Yangsi, Dulangkou and Donglu [J]. Educational Resarch, 2013(5):129-133

[4] Zhong Qiquan. The Challenges of Classroom Evaluation[J].Global Education, 2012(1):10-16

[5] Li Jing, Wen Xue. Three Typical Composition Teaching Models in Primary and Secondary Schools and their Enlightenment [J]. Curriculum, Teaching Material and Method, 2016(7):76-85

[6] Xu Kuihong. The Connotation and Characteristics of MOOC and Its Enlightenments to Lifelong Education in China [J]. Vocational and Technical Education, 2014(28): 60-63

[7] GuoYulian. On the Reform of Classroom Teaching Mode [J]. Theory and Practice of Education, 2012(10):57-60. 